\title{
Synthetic and Spectroscopic Study of the Mechanism of Atomic Layer Deposition of Tin Dioxide
}

\section{Citation}

Weimer, Matthew S., Bo Hu, Steven J. Kraft, Roy G. Gordon, Carlo U. Segre, and Adam S. Hock. 2016. "Synthetic and Spectroscopic Study of the Mechanism of Atomic Layer Deposition of Tin Dioxide." Organometallics 35 (9) (May 9): 1202-1208. doi:10.1021/acs.organomet.5b01004.

\section{Published Version}

10.1021/acs.organomet.5b01004

\section{Permanent link}

http://nrs.harvard.edu/urn-3:HUL.InstRepos:34557748

\section{Terms of Use}

This article was downloaded from Harvard University's DASH repository, and is made available under the terms and conditions applicable to Open Access Policy Articles, as set forth at http:// nrs.harvard.edu/urn-3:HUL.InstRepos:dash.current.terms-of-use\#OAP

\section{Share Your Story}

The Harvard community has made this article openly available.

Please share how this access benefits you. Submit a story.

\section{Accessibility}




\title{
A Synthetic and Spectroscopic Study of the Mechanism of Atomic Layer Deposition of Tin Dioxide
}

\author{
Matthew S. Weimer ${ }^{\dagger}$, Bo Hu ${ }^{\dagger, \ddagger}$, Steven J. Kraft ${ }^{\ddagger}$, Roy G. Gordon, ${ }^{\#}$ Carlo U. Segre ${ }^{\S}$, and Adam S. Hock ${ }^{\dagger, \ddagger, *}$ \\ ${ }^{\dagger}$ Department of Biological and Chemical Sciences, and ${ }^{\S}$ Department of Physics, Illinois Institute of Technology, 3101 South \\ Dearborn St., Chicago, Illinois, 60616, United States
}

${ }^{*}$ Harvard University, Department of Chemistry and Chemical Biology, 12 Oxford St., Cambridge, MA 02138

${ }^{\ddagger}$ Chemical Sciences and Engineering Division, Argonne National Laboratory, 9700 South Cass Ave., Argonne, Illinois, 60439, United States

\section{Supporting Information Placeholder}

\begin{abstract}
This study details the surface reaction chemistry relevant to the vapor deposition mechanism of SnO $\mathrm{S}_{2}$ thin films by atomic layer deposition. The mechanism was elucidated by combining different spectroscopic studies. Initial nucleation of cyclic $\mathrm{N}^{2}, \mathrm{~N}^{3}$-di-tert-butyl-butane-2,3-diamido tin(II) (1) consists of surface SiOH protonation of ligands as shown by diffuse reflectance infrared Fourier transform spectroscopy (DRIFTS). This $\mathrm{SiO}_{2}$-surface-bound stannylene was further characterized by X-ray absorption (XAS) and resonance Raman spectroscopy. XAS, DRIFTS and Raman spectroscopy were then used to follow the further reaction of the surface-bound stannylene with different oxygen sources and a second equivalent of $\mathbf{1}$. It was observed that water does not oxidize the initial surface bound tin site and a well-defined, three-coordinate tin(II) species, with two surface oxygen bonds and coordinated water molecule, was characterized. Treatment of the surface stannylene with protic oxidants such as $\mathrm{H}_{2} \mathrm{O}_{2}$ or $t \mathrm{BuOOH}$ fully oxidizes tin to 4+ and coordination of additional oxygen ligands is observed. When a second equivalent of $\mathbf{1}$ is added to surface bound $\mathrm{Sn}^{4+}$, the resulting surface tin is also found to be in the +4 oxidation state, contrary to the nonoxidative nucleation step. As such, surface peroxide species provide a probable growth mechanism of $\mathrm{SnO}_{2}$ through oxidation, while nucleation occurs through protic ligand exchange.
\end{abstract}

\section{INTRODUCTION}

The controlled synthesis of well-defined materials for catalytic $^{1}$ and electronic ${ }^{2}$ applications is dependent on intimate knowledge of chemical processes. This is particularly challenging for gas-solid reactions, such as in the rapidly growing field of atomic layer deposition (ALD), where sequential, stoichiometric reactions of gaseous metal and non-metal sources are used to grow a material. By far the most common strategy for deposition relies on proton transfer followed by ligand dissociation as the synthetic pathway; e.g. oxides, sulfides, and nitrides prepared from metal precursor and corresponding protic reagents $\mathrm{H}_{2} \mathrm{O}, \mathrm{H}_{2} \mathrm{~S}$ and $\mathrm{H}_{3} \mathrm{~N}$. ${ }^{3}$ In addition to water, other oxygen sources such as molecular oxygen, ozone, and hydrogen peroxide, have been used to prepare metal oxide films. In general, little attention has been paid to the role that the nonmetal 'precursor' (reagent) plays in the chemistry beyond whether it is acting as a proton-containing reagent or an oxidant. However, utilizing more complicated chemistry for ALD processes requires a detailed understanding the impact of metal and nonmetal reagents upon both nucleation and growth mechanisms.

One new synthetic strategy for growth by ALD is controlled oxidation of a lower-valent metal starting material. This is advantageous because the nature of the oxidant can control the resulting metal oxide species, has been shown in the case of iron oxides. ${ }^{4}$ Furthermore, lower valent complexes require fewer ligands and therefore can be more volatile, which has been demonstrated by our group for iron ${ }^{4}$ and tin oxides. ${ }^{5}$ In the case of tin, a low valent tin(II) precursor (Figure 1) has

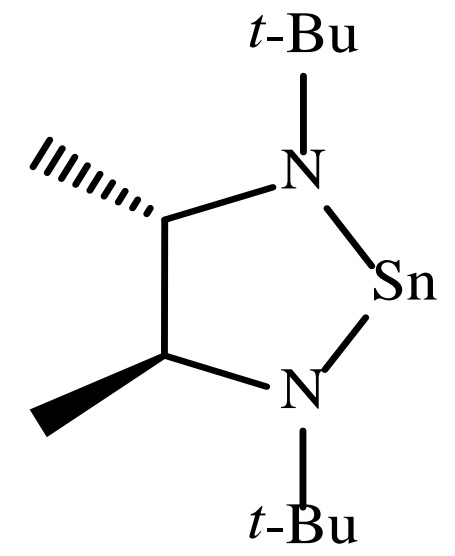

Figure 1. Stannylene, $\mathrm{N}_{2}, \mathrm{~N}_{3}$-di-tert-butyl-butane-2,3-diamido tin(II) (1), previously reported to be ALD precursor for growth of SnS with $\mathrm{H}_{2} \mathrm{~S}$ and $\mathrm{SnO}_{2}$ with $\mathrm{H}_{2} \mathrm{O}_{2}$. 
been shown to be quite versatile for the synthesis of tin chalcogenides. This tin(II) compound (1) can be used with $\mathrm{H}_{2} \mathrm{~S}$ as an ALD partner to grow the photovoltaic material $\mathrm{SnS}$ by a protonation ALD mechanism. ${ }^{6}$ Also, 1 can be used with $\mathrm{H}_{2} \mathrm{O}_{2}$ to grow $\mathrm{SnO}_{2}$ by an oxidation mechanism. Interestingly, $\mathrm{SnO}$ does not grow when $\mathrm{H}_{2} \mathrm{O}$ is used as an ALD partner. ${ }^{5}$

Since stannylenes show reactivity through oxidation as well as ligand exchange, mechanisms for ALD growth are not simple to predict. Issues arises from the ability to anticipate wether a stannylene will react throughoxidative addition versus protolytic ligand transfer, as outlined in Scheme 1. Intuitively, it is anticipated that a more acidic proton would induce protolytic ligand transfer and more basic compound could induce oxidative addition. However, Power and co-workers have established that reactivity of diarylstannylenes depends less on the $\mathrm{p} K_{\mathrm{a}}$ of the reagent or the steric bulk of the arene groups, but rather the thermodynamic stability of the products and kinetics of the reaction. For instance, the bulky stannylene $\mathrm{Sn}\left(\mathrm{Ar}^{\mathrm{Me}_{6}}\right)_{2}$, $\left[\mathrm{Ar}^{\mathrm{Me}_{6}}=\mathrm{C}_{6} \mathrm{H}_{3}-2,6-\left(\mathrm{C}_{6} \mathrm{H}_{2}-2,4,6-\left(\mathrm{CH}_{3}\right)_{3}\right)_{2}\right]$ undergoes arene elimination with $\mathrm{H}_{2}$ and $\mathrm{NH}_{3}\left(\mathrm{p} K_{\mathrm{a}}=10.5\right)$ to remain $2+{ }^{7}$ and oxidative addition with $\mathrm{HBF}_{4}\left(\mathrm{p} K_{\mathrm{a}}=-0.44\right)$ and $\mathrm{H}\left(\mathrm{SO}_{3} \mathrm{CF}_{3}\right)\left(\mathrm{p} K_{\mathrm{a}}=-14.1\right)$ to form $\mathrm{Sn}(\mathrm{IV})$ compounds. ${ }^{8}$ Complicating the matter further, stannylenes have shown a wide range of additional reactivity; coordination via the lone pair to transition metals ${ }^{9}$ or as Lewis acid-base pairs with carbenes, ${ }^{10}$ insertion, $^{11}$ reduction (disproportionation to Sn metal), cycloaddition, ${ }^{12}$ and substitution ${ }^{13}$ reactions.

ALD of $\mathrm{SnO}_{2}$ films has been successful using a wide range of precursors, ${ }^{3}$ however recent use of stannylenes have been found to grow films with superior quality and electrical properties. ${ }^{5,}{ }^{14}$ Clean, stoichiometric reactivity is absolutely necessary for ALD of quality materials, most prominently at interfaces. The stoichiometric nature of an ALD reaction, where a maximum of one mono-layer of precursor can react with the active surface species during each half-cycle, allows for the growth mechanism, in theory, to be studied with traditional solution chemistry. ${ }^{15}$ Thus the chemistry of $\mathbf{1}$ provides an ideal setting to study the solution and surface coordination chemistry of stannylenes with oxidants and hydroxide (-OH) bonds. We wish to report the discovery of the deposition mechanism reaction of a cyclic stannylene with $\mathrm{H}_{2} \mathrm{O}_{2}$.

\section{RESULTS AND DISCUSSION}

While the successful deposition of $\mathrm{SnO}_{2}$ from $\mathrm{N}^{2}, \mathrm{~N}^{3}$-di-tertbutyl-butane-2, 3-diamido tin(II) (1) and $\mathrm{H}_{2} \mathrm{O}_{2}$ has been performed for years, ${ }^{5}$ the mechanism, specifically how and when tin is oxidized, has yet to be studied in detail. Generally,

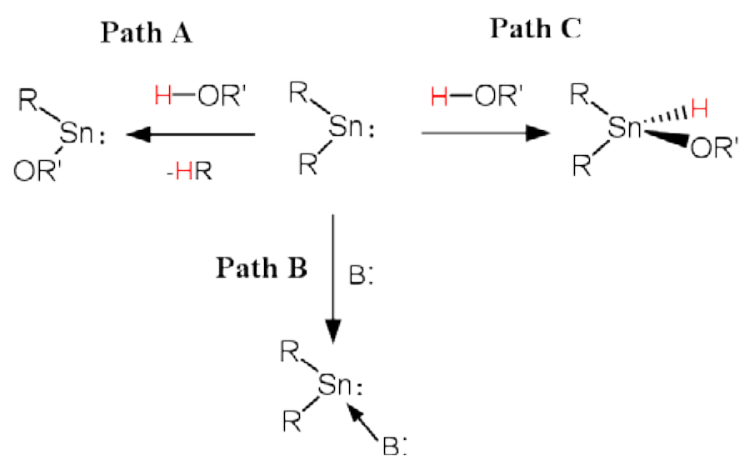

Scheme 1. Potential pathways for low valent stannylene compound with protic species. Path A is protonation reaction, Path B is Lews acid/base coordination and Path $\mathrm{C}$ is oxidative addition.

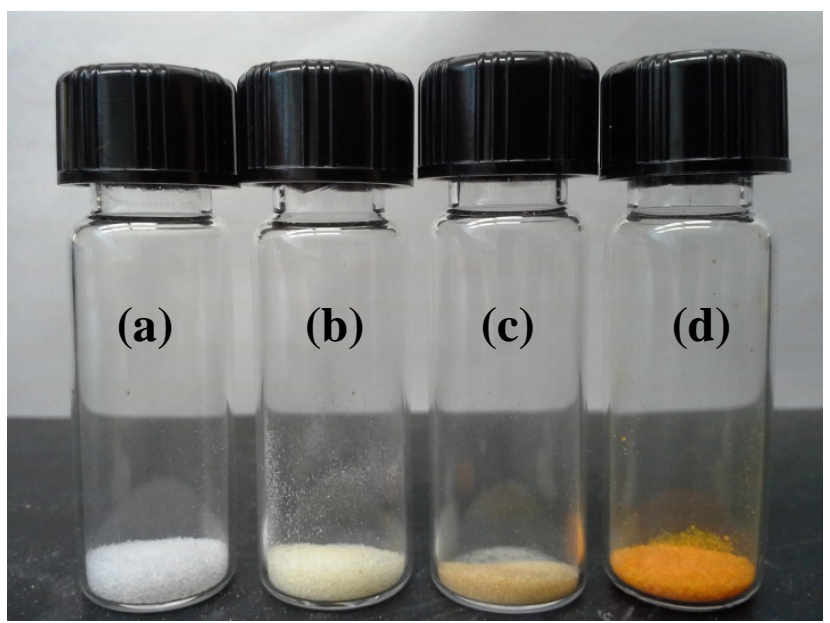

Figure 2. $\mathrm{N}^{2}, \mathrm{~N}^{3}$-di-tert-butyl-butane-2, 3-diamido tin(II) (1) molar loading levels of (a) 0 molar\%, (b)1.5 molar\%, (c) 3.0 molar\%, and (d) 4.5 molar\% on $\mathrm{SiO}_{2}$.

stannylenes have access to different reaction paths, as shown in Scheme 1, depending on the geometry and availability of the tin p-type orbitals. Low coordinate heterocyclic stannylenes show similar reactivity to the general class of stannylene mentioned above; however $\mathbf{1}$ does not have the stability of additional nitrogen $\pi$-donors to mitigate the reactivity of the unfilled p-orbital. As such, coordinately unsaturated compounds similar to $\mathbf{1}$ are expected to undergo more facile oxidative addition compared to ligand transfer/protonation or acid/base donor chemistry. Foley et. al. showed facile protonation chemistry of bis(dimethylamido) tin(II) with ethanol to give $\mathrm{Sn}(\mathrm{OR})_{2}{ }^{16}$ and Tolman and coworkers showed the conversion and isolation of a bis(amidinate)tin(II) compound to the monosubstituted alcohol was aided by the steric bulk of the reactants. ${ }^{13 \mathrm{~b}}$ Additionally, Neumann remarks how dialkyl stannylenes are expected to make Lewis acid-base donor pairs with small Lewis bases, such as $\mathrm{H}_{2} \mathrm{O} ;{ }^{17}$ unfortunately the authors are not aware of any single molecule examples of this type of Lewis acid-base compound to date. Recently, Power and coworkers found that diarlygermylenes and diarylstannylenes exhibit oxidative addition behavior with Brønsted acids. For example, $\mathrm{Ar}_{2} \mathrm{Sn}$ oxidizes to $\mathrm{Sn}(\mathrm{IV})$ with $\mathrm{HBF}_{4}{ }^{8}$. These works outline three distinct pathways for reaction with protic oxygen sources, as shown in Scheme 1; substitution through protonation, coordination of a Lewis base to the empty p-orbital of the Sn and oxidative addition to generate a $\mathrm{Sn}(\mathrm{IV})$ species.

Access to the different mechanisms of stannylene reactivity is observed in ALD literature as these types of coordinately unsaturated precursors will grow $\mathrm{SnS}^{14 \mathrm{c}}$ with $\mathrm{H}_{2} \mathrm{~S}$ and $\mathrm{SnO}_{2}$ with $\mathrm{H}_{2} \mathrm{O}_{2}$. ${ }^{5}$ Interestingly, these cyclic stannylenes do not appreciably grow $\mathrm{SnO}$ with $\mathrm{H}_{2} \mathrm{O}$ under ALD conditions. This disparate behavior is worthy of further investigation. In solution, 1 reacts with $\mathrm{H}_{2} \mathrm{O}$ and $\mathrm{H}_{2} \mathrm{O}_{2}$ to form an insoluble solid. Further investigative reactions with triphenylsilanol gave a mixture of products that were difficult to characterize by ${ }^{1} \mathrm{H}$ NMR and, in our hands, did not produce an isolable product.

To overcome the difficulty faced in solution with $\mathbf{1}$, we produced a material that contains isolated stannylenes species on dehydrated high surface-area silica $\left(\mathrm{SiO}_{2}\right)$. Synthesis of 1 with $\mathrm{SiO}_{2}$ proceeded quickly in organic solvents at room temperature where an orange solution of 1 reacts with white $\mathrm{SiO}_{2}$ to give light orange 2, as shown in Figure 2b-d. The clear mother 

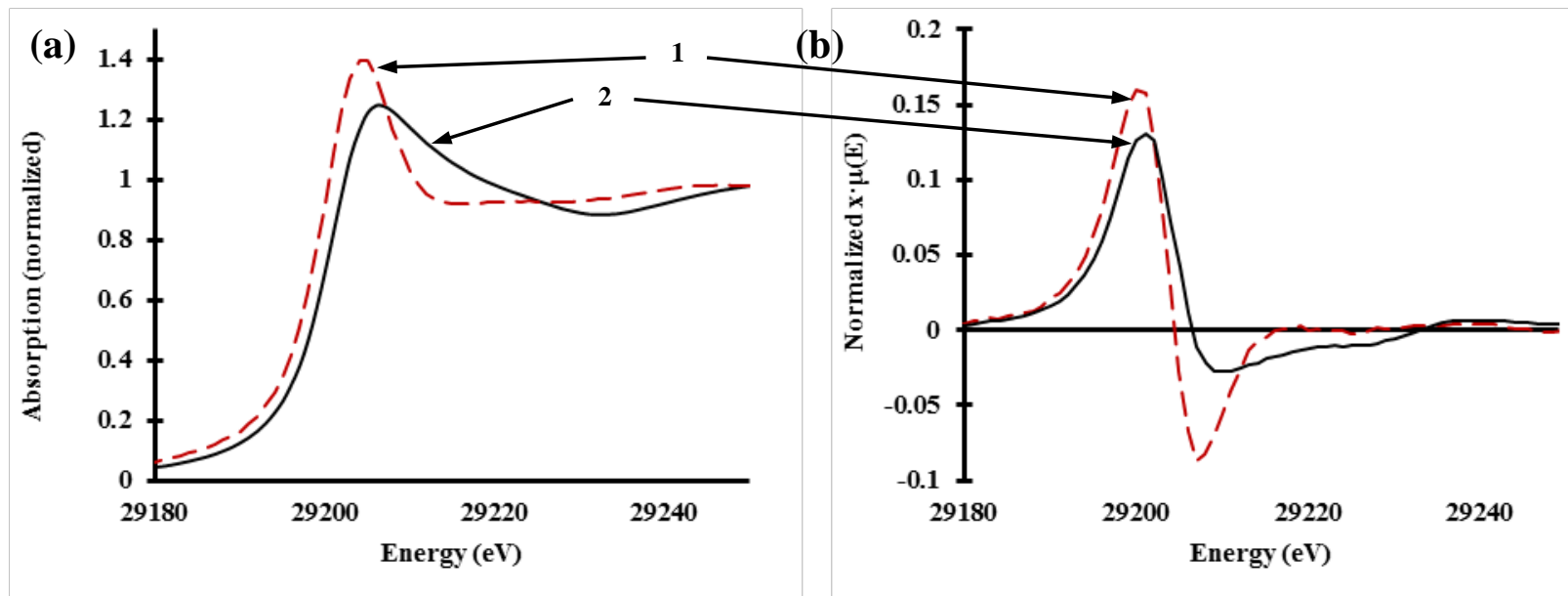

Figure 3. (a) XANES spectra of $\mathrm{N}^{2}, \mathrm{~N}^{3}$-di-tert-butyl-butane-2, 3-diamido tin(II) (1) with as deposited 2 and (b) the first derivative of the same XAS data.

liquor was devoid of starting material by ${ }^{1} \mathrm{H}$ NMR at this point and heating 2 in benzene- $\mathrm{d}_{6}$ to $60^{\circ} \mathrm{C}$ for 30 minutes showed just under an equivalent of free ligand in solution, compared to an internal standard, and was observed across molar loading on the $\mathrm{SiO}_{2}$ surface. Molar loading was kept at $1.5 \mathrm{~mol} \%$ for all further investigations. Loss of ligand around the Sn center is further supported by X-ray absorption near edge structure (XANES) spectroscopy, the excitation energy for the 1s electron or edge position is the same for the SnO standard (tabulated in the Supporting Information, Table S1), but shape is drastically different from 1, as shown in Figure 3. The change in shape is due to the difference in orbital contribution to the LUMO on $\mathrm{Sn}$ between two ${ }^{-} \mathrm{NR}_{2}$ ligands and two ${ }^{-} \mathrm{OSi}^{*}$ (OSi* indicates a surface species) ligands. Ligand exchange is also confirmed with diffuse reflectance infrared Fourier transform spectroscopy (DRIFTS). Material 2 shows a decrease in the band associated with the surface hydroxyl of high surface area silica $\left(3743 \mathrm{~cm}^{-1}\right)^{18}$ after addition of the Sn(II) precursor (1), as shown in $\mathrm{SiO}_{2}$ backgroud subtracted spectrum in Figure 4. Additionally, the spectra show the existence of protonated ligand on the surface of the $\mathrm{SiO}_{2}$, where the $\mathrm{NH}$ stretch was observed at $3310 \mathrm{~cm}^{-1}$, close to the published value of 3307 $\mathrm{cm}^{-1} .{ }^{19}$ No nitrogen was observed in the films grown by Gordon and co-workers ${ }^{5}$ and the NMR data showed release of a full equivalent of protonated ligand, it is assumed that free ligand does not interfere with the surface growth chemistry and is removed during growth conditions. To ensure isolated Sn species, we maintained a low molar loading, 0.015 moles (1.5 molar\%) of Sn/moles of surface hydroxyls (Figure 2b). The single site nature of $\mathbf{2}$ is confirmed by Raman spectroscopy, shown in Figure 5, through the absence of a peak at 580 $\mathrm{cm}^{-1}$ associated with $\mathrm{SnO}_{2}$ clusters, ${ }^{20}$ and X-ray absorption fine structure (XAFS), where approximately two first shell scattering paths (both Sn-O bonds) and no higher ordered scatters are present (Figure S1 in the Supporting Information). The lack of large clustering shown by these samples is in accord with Scotti and coworkers research on tin doped glass; a loading of less than 0.03 moles of $\mathrm{Sn} /$ moles of surface hydroxyls (3 mole\%) produces a material with isolated $\mathrm{SnO}_{2}$ sites. ${ }^{20}$ From these data we can infer that the isolated Sn species remains in the 2+ oxidation state, are approximately two coordinate and that $\mathbf{2}$ should have reactivity similar to a stannylene. Thus, we infer that $\mathbf{1}$ undergoes substitution through protonation with two neighboring surface silanol groups, generating free ligand in the process, similar to Path A in Scheme 1. To the best of the author's knowledge, this is the first observation of a surface bound stannylene by X-ray absorption spectroscopy (XAS).

After establishing the isolated nature of $\mathbf{2}$, that material was treated with water to produce a new orange material, $\mathbf{3}$, as seen in Scheme 2. By XAFS, the coordination number of $\mathbf{3}$ increased from two to three as the bond length increased from 2.05(17) to 2.11(21) $\AA$. It was determined through a difference fit that a full coordination of water is responsible for this lengthening of average bond-length. This result implies a picture where two Sn-OSi* bonds of $2.05 \AA$, one $\mathrm{Sn}-\mathrm{OH}_{2}$ bond of $2.15 \AA$, along with the $S n$ lone pair, fill the coordination sphere of the surface stannylene in a Lewis acid-base type reaction, shown in Scheme 2. This distance is in agreement with other sterically hindered stannylene-water Lewis acid-base compounds such as $\left[\mathrm{Sn}\left(18-\right.\right.$ crown-6) $\left.\left(\mathrm{H}_{2} \mathrm{O}\right)\right]\left[\mathrm{BF}_{4}\right]_{2} \cdot 2 \mathrm{H}_{2} \mathrm{O}$, where the apical water is at a distance of 2.150(7). ${ }^{21}$ Since the reactivity with $\mathrm{H}_{2} \mathrm{O}$ is a Lewis acid-base type, as shown as Path B in Scheme 1 , and not a protonation/deprotonation or oxidative addition type, the surface stannylene nature of $\mathbf{2}$ is further supported. One would also predict that $\mathbf{3}$ would be unreactive to further Sn(II) precursor and would not grow SnO by ALD.

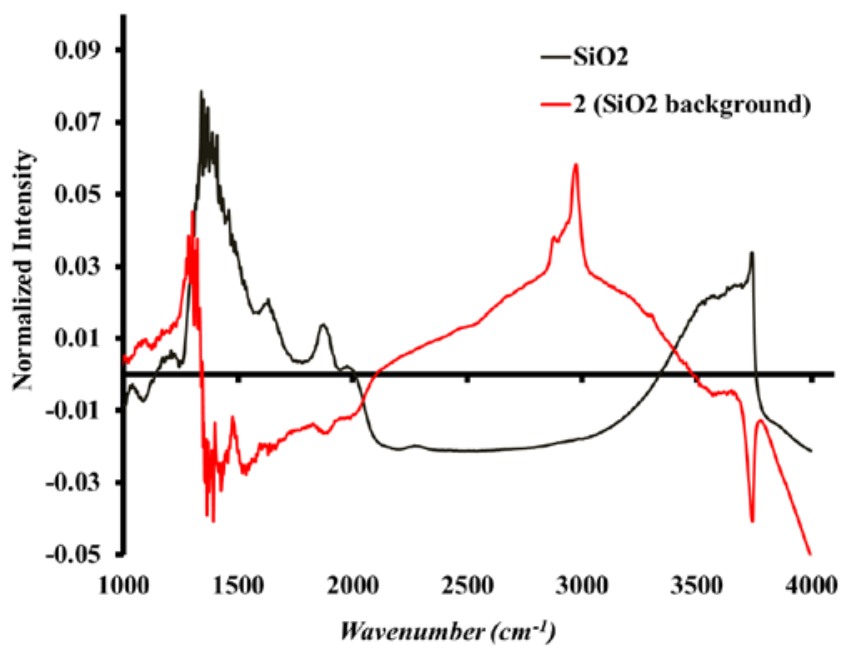

Figure 4. Diffuse reflectance infrared Fourier transform spectroscopy (DRIFTS) of unreacted silica (black) and the product of $\mathbf{1}$ with silica (2) with $\mathrm{SiO}_{2}$ as a background shown in red. 


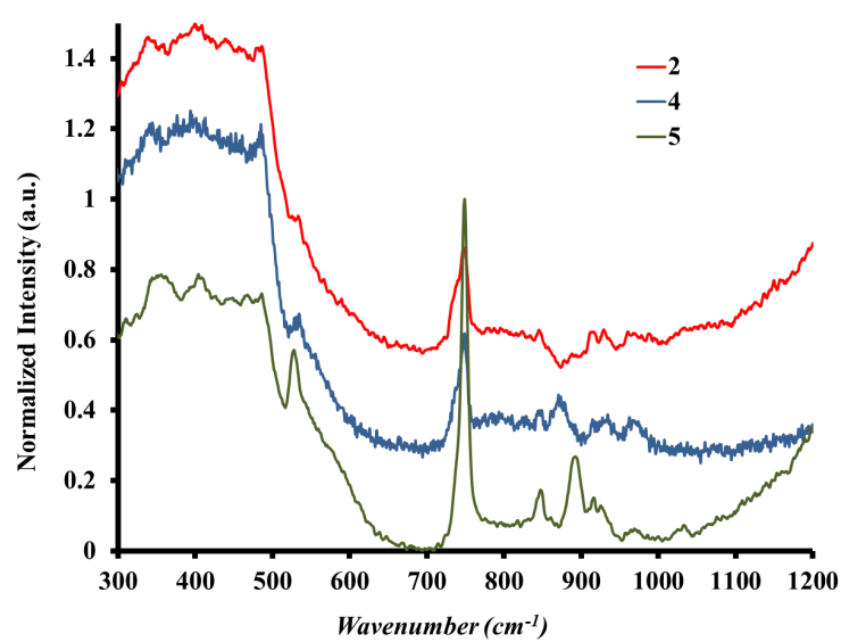

Figure 5. Raman spectra of materials 2, 4, 5 which were taken directly after the conclusion of each reaction. Spectra are offset for clarity.

When 3 was exposed to a second molar equivalent of $\mathbf{1}$ (Scheme 2), there was no change in the XAS or Raman spectra, simply a darkening in the color of the material, further discussed below.

Exposure of 2 with strong oxidant sources, $\mathrm{H}_{2} \mathrm{O}_{2}$ and $t \mathrm{BuOOH}$, gave two new white materials, 4 and 5 respectively, as characterized by XAS. The judicious choice of oxidants provides a comparison of oxidants with similar strength, but with and without the presence of $\mathrm{H}_{2} \mathrm{O}$. As expected, both peroxides fully oxidized 2 to the 4+ state, as shown by a shift of $3.94 \mathrm{eV}$ in the XANES spectrum (Table S1 of the Supporting Information). Additionally, the coordination number was found to be approximately six for $\mathbf{4}$ and $\mathbf{5}$, which are in line with the $\mathrm{Sn}-\mathrm{O}$ coordination of bulk $\mathrm{SnO}_{2}$ and significantly greater than that of SnO. Additionally, the Sn-O bond length stays 2.05 (17) $\AA$ which is only marginally longer than bulk $\mathrm{SnO}_{2}(2.042 \AA)$ and much shorter than bulk SnO (2.231 $)$. The structural similarities between $\mathbf{4}$ and $\mathbf{5}$ shows that the presence of water does not affect the proposed growth mechanism, since care was taken to exclude water in the synthesis of $\mathbf{5}$, and that $\mathbf{3}$ undergoes oxidative addition with peroxides. From Raman data we know that peroxide species exist on the surface of the high surface area silica for both $4,874 \mathrm{~cm}^{-1}$, and $5,895 \mathrm{~cm}^{-1}$ (Figure 5 above and Figures S7 and S8 of the Supporting Information). These values are in good agreement with the published vales of the $v \mathrm{O}-\mathrm{O}$ mode $\mathrm{e}^{22}$ but the resolution was not sufficient to distinguish between $\mathrm{SiO}-\mathrm{OR}$ or $\mathrm{SnO}-\mathrm{OR}$ species. From XAFS data we also see an emergence of higher shell, Sn-O-Sn, scattering after peroxide treatment, as seen in Figures S3 and S4 of the Supporting Information. This is associated with Sn agglomeration; the amount of Sn-O-Sn in $\mathbf{4}$ was calculated to be $0.24(0.32)$ and 3.49(1.37) in 5. While the uncertainty is substantial, the tin clustering is confirmed with Raman data as a peak emerging around $580 \mathrm{~cm}^{-1} .^{20}$ The distance between Sn atoms is $3.23(0.01) \AA$ for 4 and $3.30(0.14)$ $\AA$ for 5, which is longer than the bulk value of 3.17 (0.01) $\AA$ for $\mathrm{SnO}_{2}$. From these data, we infer a mechanism similar to Path $\mathrm{C}$ from Scheme 1, where oxidative addition occurs across the hydrogen oxygen bond, generating surface bound Sn(IV) species $\mathbf{4}$ and 5, from Scheme 2, with at least one peroxide ligand.

With the nucleation and oxidation chemistry consisting of protonation followed by tin oxidation, we then added a second dose of tin precursor to the well-characterized Sn(II) 2 and $\mathbf{3}$ and the Sn(IV) 4 and 5 materials to elucidate the probable ALD growth mechanism. In the same fashion as the reaction with high surface silica, $\mathbf{2}$ and $\mathbf{3}$ react with a molar equivalent of $\mathbf{1}$ quickly in organic solvent where the orange solution turns clear as the silica becomes deeper orange/brown, as seen in the higher molar loading (3.0\%) in Figure 2c. These materials showed no change in the XAS or Raman spectra, consistent with the observation that bulk $\mathrm{SnO}$ is not grown from the tin precursor 1 and $\mathrm{H}_{2} \mathrm{O}$ by ALD. Unlike the $\mathrm{Sn}(\mathrm{II})$ counterparts, the Sn(IV) materials, $\mathbf{4}$ and $\mathbf{5}$, showed novel reactivity by XAS and Raman spectroscopy. The white material of $\mathbf{4}$ and $\mathbf{5}$ was added to an orange solution of $\mathbf{1}$ and in less than 10 minutes,

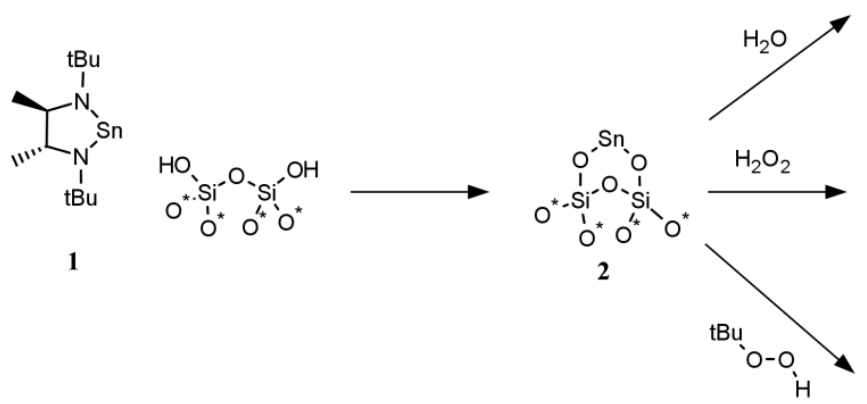

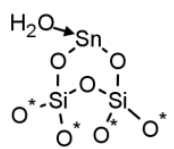

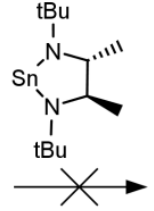

3
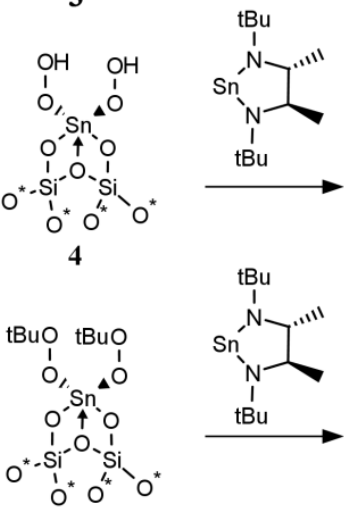

5

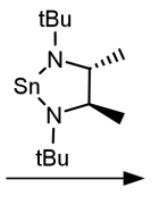

No Reaction

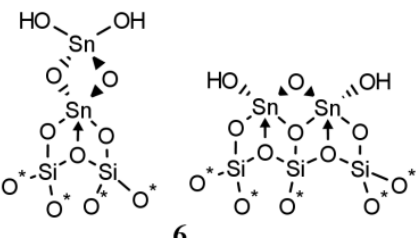

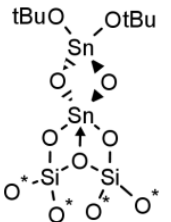

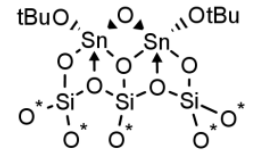

7

Scheme 2. Reaction pathways for 2 with various oxygen sources as well as a second molar equivalent of $\mathrm{N}^{2}$, $\mathrm{N}^{3}$-di-tert-butyl-butane-2, 3diamido tin(II) (1). Si-O* denotes a surface bound species. 
the solution became clear-colorless while the material remained white. These new materials, 6 and 7, showed only Sn(IV) by XANES, with no Sn(III) or Sn(II) apparent, but with an increase in the overall amount of Sn compared to 4 or 5. The XAFS spectra of $\mathbf{6}$ and $\mathbf{7}$ were essentially unchanged with respect to bond distances and coordination with respect to 4 and 5. This means that the surface peroxide species observed in $\mathbf{4}$ and 5 are responsible for the complete oxidation of all newly introduced 1 to Sn(IV) and an excess of protons (from $\mathrm{H}_{2} \mathrm{O}_{2}$ or $t \mathrm{BuOOH}$ ) is responsible for the removal of the diamido ligand. Disappearance of the $v$ O-O mode in the Raman spectrum of $\mathbf{6}$ and 7 further supports the peroxide driven mechanism purposed (Figures S7 and S8 Supporting Information). Thus it appears that a low coordinate stannylene will react with surface peroxide species ( $\mathrm{Sn}$ or $\mathrm{Si}$ ) in a manner similar to Path $\mathrm{C}$ in Scheme 1 faster than a proton transfer in Path A. Unlike the initial nucleation by the protic ligand transfer mechanism, the steady state growth mechanism likely involves the newly introduced stannylene insertion into a O-O bond of the peroxide, as shown on the left side of Scheme 2, and requires more peroxide to generate a reactive surface species which allows for ALD type growth. Thus, the mechanism for ALD growth of $\mathrm{SnO}_{2}$ is as follows. First, 1 undergoes ligand exchange, by protonolysis, with surface hydroxyls to form a two coordinate surface stannylene (2). Then a peroxide molecule oxidizes the surface stannylene, while excess $\mathrm{H}_{2} \mathrm{O}_{2}$ regenerates reactive surface peroxide species (4). Further vapor phase stannylene molecules react with the surface peroxide species, oxidatively inserting into the $\mathrm{O}-\mathrm{O}$ bond and creating all Sn(IV) surface species (6). This insertion and oxidation occurs at a rate much faster than protonolysis and ALD growth temperatures would limit the thermal lifetime of the surface bound peroxide species.

\section{CONCLUSIONS}

In summary, we have mapped the likely deposition mechanism of a low-coordinate stannylene molecule, $\mathrm{N}^{2}, \mathrm{~N}^{3}$-di-tertbutyl-butane-2, 3-diamido tin(II) (1), which successfully grows $\mathrm{SnO}_{2}$ but not $\mathrm{SnO}$ by ALD with high surface-area silica and three oxygen sources. X-ray absorption spectroscopy (XAS), diffuse reflectance infrared Fourier transform spectroscopy (DRIFTS) and Raman spectroscopy show that the initial nucleation of $\mathbf{1}$ with the surface is nonoxidative. The surface stannylene contains isolated $\mathrm{Sn}(\mathrm{II})$ species that bind water without change in oxidation state. This new material, 3, provided an example of a $\mathrm{H}_{2} \mathrm{O}$-stannylene Lewis acid-base complex. The surface stannylene reacts via well-defined oxidative addition with both aqueous and nonaqueous peroxide sources to yield surface Sn(IV). A "second dose" of $\mathbf{1}$ did not produce a reaction with the water-coordinated tin(II) stannylene but surface peroxide groups bound to tin (IV) fully oxidized the second dose of tin precursor to $4+$ without the observance of tin deposition in lower oxidation states. The thermal stability of the surface-bound tin(IV) peroxide is likely process-limiting for the growth of ALD $\mathrm{SnO}_{2}$ with precursor 1.

\section{EXPERIMENTAL SECTION}

General consideration: All chemical manipulations were carried out using standard Schlenk techniques or in a glove box (Vacuum Atmosphere) in a dry nitrogen atmosphere, with the exception of $\mathrm{H}_{2} \mathrm{O}$ and $\mathrm{H}_{2} \mathrm{O}_{2}$ treatments. Pentane, diethyl ether, tetrahydrofuran (THF), toluene, benzene and hexane were dried by argon assisted movement over two columns (one neutral alumina column and one copper (II) oxide-Q5 column for pentane, toluene, benzene, and hexane and two neutral alumina for diethyl ether and THF), stored over $4 \AA$ molecular sieves and tested periodically with sodium benzophenone ketyl. ${ }^{23}$ Synthesis of $\mathrm{N}^{2}, \mathrm{~N}^{3}$-di-tert-butyl-butane-2, 3-diamido tin(II) (1) was performed according to literature procedures. ${ }^{5}$ Hydrogen peroxide (30\% in water from Sigma Aldrich), tert-butyl hydroperoxide (5 M in decane from Sigma Aldrich) and deionized water were deoxygenated with a moderate $\mathrm{N}_{2}$ flow for a minimum of 15 minutes directly prior to use. High surface-area silica (Sigma Aldrich 250-500 $\mu \mathrm{m}, 35-60$ mesh, $1.15 \mathrm{~cm}^{3}$ pore volume, $150 \AA$ pore size) was heated to $150^{\circ} \mathrm{C}$ under reduced pressure ( $\sim 25$ mtorr) for over five hours to remove chemisorbed water. All other reagents were obtained from commercial suppliers and used as received. IR data were taken in diffuse reflection mode on a BRUKER FTIR model ALPHA-R spectrophotometer in DRIFT mode with a gold sample holder. Surface Raman measurements were taken with a red laser $(785 \mathrm{~nm})$ on a Renishaw spectrophotometer in a back scattering configuration, using a Renishaw CCD camera and a $1200 \mathrm{~nm}$ slit. ${ }^{1} \mathrm{H}(300 \mathrm{MHz})$ NMR spectra were recorded on a Bruker 300, at ambient temperature and referenced to internal protio resonances. ${ }^{24} \mathrm{NMR}$ solvent was received from Cambridge Isotopes and dried over $4 \AA$ molecular sieves for a minimum of 48 hours prior to use.

$\mathrm{Sn}(\mathrm{II}) @ \mathrm{SiO}_{2}$ (2). Absorption of 1 on high surface are silica was performed by dissolving $77 \mathrm{mg}(0.243 \mathrm{mmol})$ of 1 in $10 \mathrm{ml}$ pentane or hexane with a Teflon stir bar in a scintillation vial. Slowly, $1 \mathrm{~g}$ high surface area silica was added and the orange solution was allowed to stir for one hour. The solution turned colorless within 10-30 minutes with a simultaneous color change of the silica to light orange. After this time, the solvent was removed under reduced pressure. This combination gave $2.9 \mathrm{wt} \%$ or $1.5 \mathrm{~mol} \%$ of the desired product. Removal of free ligand was observed by ${ }^{1} \mathrm{H}$ NMR when a small amount of 2 was heated to $60^{\circ} \mathrm{C}$ in $1 \mathrm{ml} \mathrm{C}_{6} \mathrm{D}_{6}$.

Oxygen source treatment of 2 . Reactions were carried out on 2 with different oxygen sources; $\mathrm{H}_{2} \mathrm{O}$ (3), $\mathrm{H}_{2} \mathrm{O}_{2}$ (4), and ${ }^{t} \mathrm{BuOOH}$ (5). An indicative example with is given below.

A $100 \mathrm{ml}$ round bottom flask with Teflon stir bar and $15 \mathrm{ml}$ pentane was charged with $960 \mathrm{mg}$ of 2 then capped with a rubber stopper. Under nitrogen flow, $0.45 \mathrm{ml}$ of tert-butyl hydroperoxide in decane (5.0 M, $2.25 \mathrm{mmol}$ ) was added and the mixture was allowed to stir for one hour. The solid turned colorless immediately. Volatile components were removed under reduced pressure and $\mathbf{5}$ was further dried with $5 \mathrm{ml}$ toluene.

$\mathbf{3}$ and $\mathbf{4}$ were synthesized in the same fashion with de-oxygenated water as the solvent and without the toluene drying step.

Addition of second diamido (1) treatment to 3, 4 and 5. Deposition of additional molar equivalent of $\mathbf{1}$ was performed on all three oxygen source treatments to give two new materials 6 from $\mathrm{H}_{2} \mathrm{O}_{2}$, and 7 from ${ }^{t} \mathrm{BuOOH}$. A control was performed by addition of a second molar equivalent of $\mathbf{1}$ to $\mathbf{2}$. A typical experiment is outlined below.

In a scintillation vial with Teflon stir bar was added $12 \mathrm{mg}(0.037$ mmol) of $\mathbf{1}$, then $5 \mathrm{ml}$ pentane. Then, $288 \mathrm{mg}$ of $\mathbf{5}$ is added slowly and the mixture is allowed to stir for one hour. The orange solution turned colorless immediately for both $\mathbf{4}$ and $\mathbf{5}$ while the solid stayed colorless. With $\mathbf{2}$ and $\mathbf{3}$ the solid darkened in orange-red color as the solution became colorless.

X-ray absorption spectroscopy experiments and data fitting techniques

All x-ray experiments were carried out in Sector 10 at hutch 10$\mathrm{BM}$ of The Materials Research Collaborative Access Team (MRCAT) at the Advanced Photon Source (APS). References and samples were pulverized in a mortar and pestle, in the amount of approximately $0.024 \mathrm{mmol}$ of Sn, loaded and pressed into sample holders in an airtight reactor, with kapton window, while under nitrogen atmosphere in a glove box. To ensure sufficient volume of sample, boron nitride was used for $\mathbf{1}$ and silica was used to supplement for all other samples. X-ray absorption spectroscopy (XAS) measurements were carried out around the Sn K edge $\left(\mathrm{E}_{0}-29.2 \mathrm{keV}\right)$ and collected in transmission mode using ionization gas chambers filled with only argon. Energy of X-ray photons was calibrated using a Sn metal foil, which was placed between the second and third gas chambers. Spectra were 
taken from $-250 \mathrm{eV}$ below to $800 \mathrm{eV}$ above the absorption edge. Xray absorption near edge structure (XANES) data were processed with the ATHENA program.

Extended X-ray absorption fine structure spectroscopy (XAFS) data curve fitting was performed in ATREMIS (version 0.8.014) and IFEFFIT software (version 1.2.11) by the FEFF program $(0.8 .061)^{25}$ and by WinXAS (version 1.1). Scattering paths were calculated from $\mathrm{SnO}_{2}{ }^{26}$ and $\mathrm{SnO}^{27}$ crystallographic information, as well as "quick first shell approximations" by FEFF for comparison. Data had the preedge and postedge backgrounds subtracted and then normalized to edge height. Background removal was accomplished through a seven domain cubic-spline with $k$-weight of two. To determine the phases and amplitudes, those data were Fourier transformed (FT) into R space, then back-Fourier transformed into $k$ space. Amplitude reduction factors $\left(\mathrm{S}_{0}{ }^{2}\right)$ were determined by using four scattering paths generated in IFEFFIT for $\mathrm{SnO}$ and $\mathrm{SnO}_{2}$ while setting the coordination number of the scatters to the known crystal structures. These values were determined to be 0.97 for Sn(IV) species and 1.16 for the Sn(II) species (due to $\mathrm{SnO}_{2}$ contamination) and thus set to 1. Coordination numbers of shells in unknown samples were then determined by setting $\mathrm{S}_{0}{ }^{2}$ and allowing the coordination number of the paths to vary independently. The disorder factor $\left(\Delta \sigma^{2}\right)$, coordination number $(\mathrm{N})$ and scattering distance (R) were then generated in this fashion from the experimental data (full tabulated data can be found in the Supplementary Information).

WinXAS fits were performed as followed. After normalization, in the same fashion as before, and XANES analysis by inspection of the first derivative of the Sn $K$ edge position, phase and amplitude references were extracted from the published crystal structure for the Sn-O path in $\mathrm{SnO}_{2}{ }^{26}$. Once these parameters were experimentally determined, chemically realistic fits were attempted using a basic leastsquares refinement. This was accomplished by allowing the program to find a best fit, then setting the $\Delta \sigma^{2}$ to provide realistic coordination numbers for the Sn-O path (full tabulated data can be found in the Supplementary Information).

\section{ASSOCIATED CONTENT}

\section{Supporting Information}

Athena and WinXAS fit information table for compounds 2-7 with standards and XAFS figures for compounds 2-5, Raman spectroscopy data for compounds 2-7 and controls and Diffuse reflectance infrared Fourier transform spectroscopy (DRIFTS) data for compounds $\mathbf{3}$ and $\mathbf{5}$ is available free of charge via the Internet at http://pubs.acs.org.

\section{AUTHOR INFORMATION}

\section{Corresponding Author}

*Adam S. Hock, ahock@iit.edu

\section{Notes}

The authors declare no competing financial interests.

\section{ACKNOWLEDGMENT}

M.S.W acknowledges support by the Department of Education GAANN Fellowship under grant \#P200A090137. B.H. is thankful for a Starr Fieldhouse Fellowship. S.J.K. acknowledges the Department of Energy Contract No. DE-AC02-06CH11357. A.S.H. would like to thank the Department of Energy and the Illinois Institute of Technology for funding and startup support. MRCAT operations are supported by the Department of Energy and the MRCAT member institutions. The authors also thank Dr. Jeff Miller for assistance with XAS data analysis and Dr. Aditya Unni for donation of tert-butyl hydroperoxide.

\section{REFERENCES}

1. (a) Tada, M.; Iwasawa, Y. Coord. Chem. Rev. 2007, 251, 27022716. (b) Chen, J.; Lim, B.; Lee, E. P.; Xia, Y. Nano Today 2009, 4, 81-95. (c) Bordiga, S.; Groppo, E.; Agostini, G.; van Bokhoven, J. A.; Lamberti, C. Chem. Rev. 2013, 113, 1736-1850.

2. (a) Kingon, A.; Maria, J.; Streiffer, S. Nature 2000, 406, 10321038. (b) Markovich, G.; Collier, C. P.; Henrichs, S. E.; Remacle, F.; Levine, R. D.; Heath, J. R. Acc. Chem. Res. 1999, 32, 415-423.

3. (a) Miikkulainen, V.; Leskelä, M.; Ritala, M.; Puurunen, R. L. J. Appl. Phys. 2013, 113, 021301. (b) Puurunen, R. L. J. Appl. Phys. 2005, 97, 121301; (c) Gordon, R. G. in Atomic Layer Deposition for Semiconductors, C. S. Hwang and C. Y. Yoo (Springer, 2014),.

4. Riha, S. C.; Racowski, J. M.; Lanci, M. P.; Klug, J. a; Hock, A. S.; Martinson, A. B. F. Langmuir 2013, 29, 3439-3445.

5. Heo, J.; Hock, A. S.; Gordon, R. G. Chem. Mater. 2010, 22, 4964-4973.

6. Kim, S. B.; Sinsermsuksakul, P.; Pike, R. D.; Gordon, R. G. Chem. Mater. 2014, 26, 3065-3073.

7. Peng, Y.; Guo, J.-D.; Ellis, B. D.; Zhu, Z.; Fettinger, J. C.; Nagase, S.; Power, P. P. J. Am. Chem. Soc. 2009, 131, 16272-16282.

8. Brown, Z. D.; Erickson, J. D.; Fettinger, J. C.; Power, P. P. Organometallics 2013, 32, 617-622.

9. (a) Hahn, F. E.; Zabula, A. V; Pape, T.; Hepp, A.; Tonner, R.; Haunschild, R.; Frenking, G. Chemistry 2008, 14, 10716-10721; (b) Akkari, A.; Byrne, J. J.; Saur, I.; Rima, G.; Gornitzka, H.; Barrau, J. J. Organomet. Chem. 2001, 622, 190-198.; (c) Saur, I.; Rima, G.; Miqueu, K.; Gornitzka, H.; Barrau, J. J. Organomet. Chem. 2003, 672, 77-85.; (d) Jana, A.; Roesky, H. W.; Schulzke, C.; Samuel, P. P. Inorg. Chem. 2010, 49, 3461-3464.; for select examples.

10. Gehrhus, B.; Hitchcock, P. B.; Lappert, M. F. J. Chem. Soc. Dalt. Trans. 2000, 3094-3099.

11. (a) Cotton, J. D.; Davidson, P. J.; Lappert, M. F.; Donaldson, J. D.; Silvet, J. J. Chem. Soc. Dalt. Trans. 1976, 2286; (b) Meltzer, A.; Inoue, S.; Präsang, C.; Driess, M. J. Am. Chem. Soc. 2010, 132, 3038-3046; (c) Saito, M.; Tokitoh, N.; Okazaki, R. Organometallics 1995, 14, 3620-3622; (d) Veith, M.; Müller, A. J. Organomet. Chem. 1988, 342, 295-301.

12. (a) Cotton, J. D.; Davidson, P. J.; Lappert, M. F. J. Chem. Soc. Dalt. Trans. 1976, 2275; (b) Lappert, M. F.; Misra, M. C.; Onyszchuk, M.; Rowe, R. S.; Power, P. P.; Slade, M. J. J. Organomet. Chem. 1987, 330, 31-46; (c) Foley, S. R.; Yap, G. P. a.; Richeson, D. S. J. Chem. Soc. Dalt. Trans. 2000, 1663-1668; (d) Zhou, D.; Reiche, C.; Nag, M.; Soderquist, J. A.; Gaspar, P. P. Organometallics 2009, 28, 2595-2608.

13. (a) Harris, D. H.; Lappert, M. F. J. Chem. Soc., Chem. Comm. 1974, 895; (b) Aubrecht, K. B.; Hillmyer, M. A.; Tolman, W. B. Macromolecules 2002, 35, 644-650; (c) Gans-Eichler, T.; Gudat, D.; Nieger, M. Angew. Chemie Int. Ed. 2002, 41, 1888.

14. (a) Sinsermsuksakul, P.; Hartman, K.; Bok Kim, S.; Heo, J.; Sun, L.; Hejin Park, H.; Chakraborty, R.; Buonassisi, T.; Gordon, R. G. Appl. Phys. Lett. 2013, 102, 053901; (b) Sinsermsuksakul, P.; Chakraborty, R.; Kim, S. B.; Heald, S. M.; Buonassisi, T.; Gordon, R. G. Chem. Mater. 2012, 24, 4556-4562; (c) Sinsermsuksakul, P.; Heo, J.; Noh, W.; Hock, A. S.; Gordon, R. G. Adv. Energy Mater. 2011, 1, $1116-1125$.

15. Fix, R. M.; Gordon, R. G.; Hoffman, D. M. J. Am. Chem. Soc. 1990, 112, 7833-7835.

16. Foley, P.; Zeldin, M. Inorg. Chem. 1975, 14, 2264-2267.

17. Neumann, W. P. Chem. Rev. 1991, 91, 311-334.

18. Morrow, B. A.; McFarlan, A. J. J. Non-Crys. Solids 1990, 120, $61-71$.

19. Gardiner, M. G.; Raston, C. L. Inorg. Chem. 1995, 34, 42064212.

20. Chiodini, N.; Morazzoni, F.; Paleari, A.; Scotti, R.; Spinolo, G. J. Mater. Chem. 1999, 9, 2653-2658 
21. Beattie, C.; Farina, P.; Levason, W.; Reid, G. Dalton Trans. 2013, 42, 15183-15190.

22. Venkateswaran, S. Nature 1931, 127, 406-406.

23. Pangborn, A. B.; Giardello, M. A.; Grubbs, R. H.; Rosen, R. K.; Timmers, F. J. Organometallics 1996, 15, 1518-1520.

24. Gottlieb, H. E.; Kotlyar, V.; Nudelman, A. J. Org. Chem. 1997, 62, 7512-7515.

25. (a) Newville, M. J. Synchrotron Radiat. 2001, 8, 322-324. (b) Ravel, B.; Newville, M. J. Synchrotron Radiat. 2005, 12, 537-41. (c) Ravel, B. J. Synchrotron Radiat. 2001, 8, 314-316.

26. Yamanaka, T.; Kurashima, R.; Mimaki, J. Zeitschrift für Kristallographie 2000, 215, 424.

27. Batzill, M.; Diebold, U. Prog. Surf. Sci. 2005, 79, 47-154.

Table of Contents artwork:

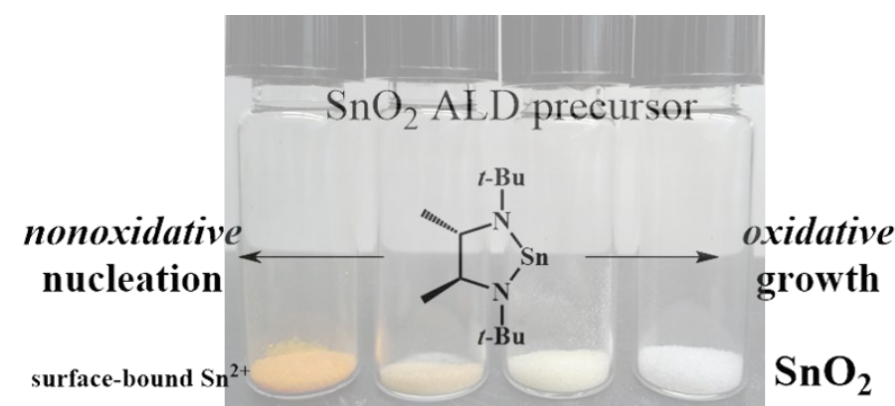




\title{
Supporting Information for: A Synthetic and Spectroscopic Study of the Mechanism of Atomic Layer Deposition of Tin Chalcogenides
}

\author{
Matthew S. Weimer ${ }^{\dagger}$, Bo Hu ${ }^{\dagger, \neq}$, Steven J. Kraft ${ }^{\ddagger}$, Roy G. Gordon, ${ }^{\#}$ Carlo U. Segre ${ }^{\S}$, and Adam S. Hock ${ }^{\dagger, \neq, *}$ \\ ${ }^{\dagger}$ Department of Biological and Chemical Sciences, and §Department of Physics, Illinois Institute of Technology, 3101 South \\ Dearborn St., Chicago, Illinois, 60616, United States \\ ${ }^{\#}$ Harvard University, Department of Chemistry and Chemical Biology, 12 Oxford St., Cambridge, MA 02138 \\ ${ }^{\ddagger}$ Chemical Sciences and Engineering Division, Argonne National Laboratory, 9700 South Cass Ave., Argonne, Illinois, \\ 60439, United States
}

Table of Contents

S1. Athena and WinXAS fit information table for compounds 2-7 with standards and XAFS figures for compounds 2-5

S2. Raman spectroscopy data for compounds 2-7

S3. Diffuse reflectance infrared Fourier transform spectroscopy (DRIFTS) data for compounds $\mathbf{2}, \mathbf{3}$ and $\mathbf{5}$ 


\section{S1. ATHENA AND WINXAS FIT INFORMATION TABLE FOR COMPOUNDS 2-7 WITH STANDARDS AND XAFS FIGURES FOR COMPOUNDS 2-5}

Table S1: Data for Artemis fits and amplitude reduction factor determination for unknown and reference compounds (values in bold were not allowed to vary).

\begin{tabular}{|c|c|c|c|c|c|c|c|c|c|}
\hline Compound & Path & amp & $\mathrm{R}(\AA)$ & $\mathrm{N}$ & $\sigma^{2}(\AA)$ & $\begin{array}{c}\Delta \mathrm{E}_{\mathrm{o}} \\
(\mathrm{eV})\end{array}$ & $\begin{aligned} \mathrm{Chi}^{2} & \text { (re- } \\
\text { duced) } & \end{aligned}$ & $\begin{array}{l}\text { R- } \\
\text { ractor } \\
(\%)\end{array}$ & $\begin{array}{l}\text { Edge Jump } \\
(\mathrm{eV})\end{array}$ \\
\hline $\mathrm{SnO}_{2}$ & $\begin{array}{l}\text { Sn-O } \\
\text { Sn-O } \\
\text { Sn-Sn } \\
\text { Sn--O }\end{array}$ & $\begin{array}{c}0.96 \\
(0.15)\end{array}$ & $\begin{array}{c}2.031 \\
(0.009) \\
2.064 \\
(0.009) \\
3.170 \\
(0.009) \\
3.567 \\
(0.009)\end{array}$ & $\begin{array}{l}4.000 \\
2.000 \\
2.000 \\
4.000\end{array}$ & $\begin{array}{c}0.0018 \\
(0.0017) \\
0.0015 \\
(0.0017)\end{array}$ & $\begin{array}{l}3.04 \\
(1.73)\end{array}$ & 11598.00 & 6.60 & 29206.048 \\
\hline $\mathrm{SnO}$ & $\begin{array}{l}\text { Sn-O } \\
\text { Sn-Sn } \\
\text { Sn-O-O } \\
\text { Sn--Sn } \\
\text { Sn---Sn }\end{array}$ & $\begin{array}{c}1.16 \\
(0.15)\end{array}$ & $\begin{array}{c}2.231 \\
(0.008) \\
3.554 \\
(0.008) \\
3.580 \\
(0.008) \\
3.706 \\
(0.008) \\
3.815 \\
(0.008)\end{array}$ & $\begin{array}{l}4.000 \\
4.000 \\
8.000 \\
4.000 \\
4.000\end{array}$ & $\begin{array}{c}0.0087 \\
(0.0024) \\
0.0066 \\
(0.0016)\end{array}$ & $\begin{array}{c}6.81 \\
(0.96)\end{array}$ & 2900.00 & 7.30 & 29202.028 \\
\hline 2 & Sn-O & 1.000 & $\begin{array}{r}2.05 \\
(0.178)\end{array}$ & $\begin{array}{c}2.64 \\
(0.15)\end{array}$ & $\begin{array}{c}0.0084 \\
(0.0010)\end{array}$ & $\begin{array}{r}3.57 \\
(0.66)\end{array}$ & 30.21 & 5.20 & 29201.052 \\
\hline 3 & Sn-O & 1.000 & $\begin{array}{c}2.07 \\
(0.154)\end{array}$ & $\begin{array}{c}3.01 \\
(0.17)\end{array}$ & $\begin{array}{c}0.0070 \\
(0.0009)\end{array}$ & $\begin{array}{c}3.93 \\
(0.63)\end{array}$ & 44.89 & 5.20 & 29202.028 \\
\hline 4 & $\begin{array}{l}\text { Sn-O } \\
\text { Sn-Sn }\end{array}$ & 0.970 & $\begin{array}{c}2.05 \\
(0.015) \\
3.23 \\
(0.013)\end{array}$ & $\begin{array}{c}5.42 \\
(0.39) \\
0.24 \\
(0.32)\end{array}$ & $\begin{array}{c}0.0056 \\
(0.0010) \\
0.0032 \\
(0.0073)\end{array}$ & $\begin{array}{c}4.23 \\
(0.79)\end{array}$ & 94.23 & 13.50 & 29204.996 \\
\hline $\begin{array}{l}3 \text { with } 2^{\text {nd }} \\
\text { addition of } 2\end{array}$ & $\mathrm{Sn}-\mathrm{O}$ & 1.000 & $\begin{array}{c}2.08 \\
(0.143)\end{array}$ & $\begin{array}{c}2.89 \\
(0.13)\end{array}$ & $\begin{array}{c}0.0063 \\
(0.0007)\end{array}$ & $\begin{array}{c}4.94 \\
(0.51)\end{array}$ & 38.23 & 3.65 & 29201.052 \\
\hline 6 & $\begin{array}{l}\text { Sn-O } \\
\text { Sn-Sn }\end{array}$ & 0.970 & $\begin{array}{c}2.049 \\
(0.007) \\
3.25 \\
(0.091)\end{array}$ & $\begin{array}{c}5.76 \\
(0.35) \\
1.49 \\
(0.90)\end{array}$ & $\begin{array}{c}0.0057 \\
(0.0008) \\
0.0086 \\
(0.0045)\end{array}$ & $\begin{array}{c}3.81 \\
(0.71)\end{array}$ & 101.36 & 8.82 & 29204.996 \\
\hline 7 & $\begin{array}{l}\text { Sn-O } \\
\text { Sn-Sn }\end{array}$ & 0.970 & $\begin{array}{c}2.04 \\
(0.011) \\
3.28 \\
(0.111)\end{array}$ & $\begin{array}{c}6.11 \\
(0.26) \\
3.41 \\
(0.89)\end{array}$ & $\begin{array}{c}0.0065 \\
(0.0006) \\
0.0124 \\
(0.0026)\end{array}$ & $\begin{array}{c}4.86 \\
(0.47)\end{array}$ & 38.21 & 3.54 & 29204.020 \\
\hline $\begin{array}{l}2 \text { with } 2^{\text {nd }} \\
\text { addition of } 2\end{array}$ & $\mathrm{Sn}-\mathrm{O}$ & 1.000 & $\begin{array}{c}2.03 \\
(0.203)\end{array}$ & $\begin{array}{r}2.21 \\
(0.18)\end{array}$ & $\begin{array}{c}0.0076 \\
(0.013)\end{array}$ & $\begin{array}{c}1.78 \\
(0.94)\end{array}$ & 32.89 & 9.70 & 29201.089 \\
\hline
\end{tabular}


Table S2: Data for WinXAS fits for unknown and reference samples (uncertainty is approximately 10\%).

\begin{tabular}{|c|c|c|c|c|c|c|c|}
\hline Compound & Edge Energy (keV) & Oxidation State & Scatter & $\mathrm{N}$ & $\mathrm{R}(\AA)$ & $\Delta \sigma^{2}\left(\mathrm{x} 10^{3}\right)$ & $\mathrm{E}_{\mathrm{o}}(\mathrm{eV})$ \\
\hline $\mathrm{SnO}_{2}$ & 29.2046 & IV & $\mathrm{Sn}-\mathrm{O}$ & 6 & 2.05 & 0.0 & 0.2 \\
\hline 1 & 29.1994 & II & & & & & \\
\hline 3 & 29.2000 & II & $\mathrm{Sn}-\mathrm{O}$ & 2.9 & 2.11 & 4.0 & 2.0 \\
\hline $\begin{array}{l}3 \\
\text { (difference Fit) }\end{array}$ & - & - & $\begin{array}{l}\mathrm{Sn}-\mathrm{O} \\
\left(\mathrm{H}_{2} \mathrm{O}\right)\end{array}$ & 1.0 & 2.15 & 1.0 & 3.4 \\
\hline 4 & 29.2031 & IV & $\mathrm{Sn}-\mathrm{O}$ & 4.9 & 2.05 & 3.0 & -3.3 \\
\hline 5 & 29.2040 & IV & $\mathrm{Sn}-\mathrm{O}$ & $\begin{array}{l}6.0 \\
5.4\end{array}$ & $\begin{array}{l}2.03 \\
2.03\end{array}$ & $\begin{array}{l}5.0 \\
3.0\end{array}$ & $\begin{array}{l}-5.2 \\
-5.2\end{array}$ \\
\hline $\begin{array}{l}3 \text { with } 2^{\text {nd }} \\
\text { Addition of } 2\end{array}$ & 29.2000 & II & Sn-O & 2.9 & 2.09 & 4.0 & -1.1 \\
\hline $\begin{array}{l}2 \text { with } 2^{\text {nd }} \\
\text { addition of } 2\end{array}$ & 29.1997 & II & Sn-O & 2.0 & 2.03 & 3.0 & -4.0 \\
\hline
\end{tabular}


Figure S1: XAFS data in R and k space for 2 with corresponding fit calculated in the Artemis program.

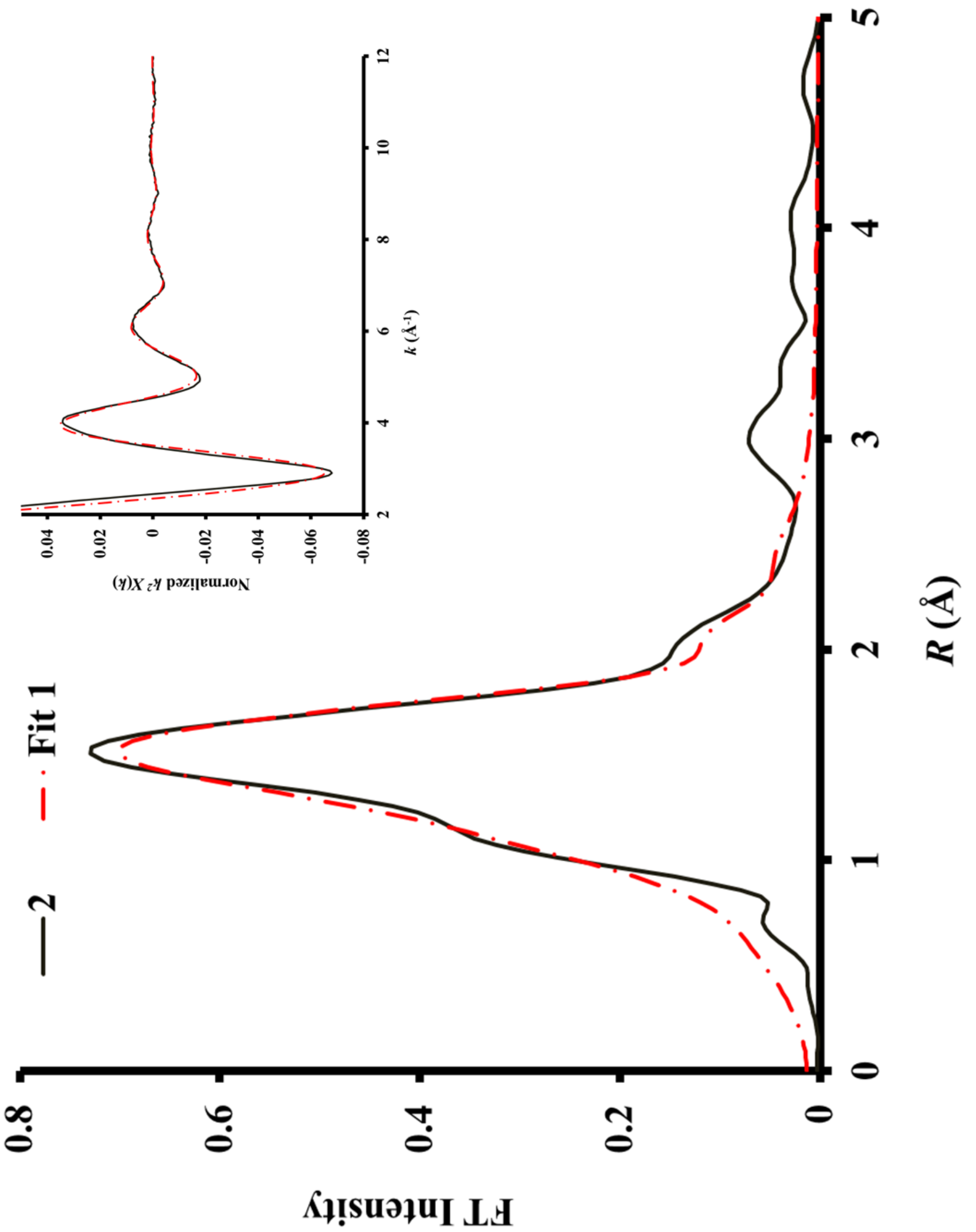


Figure S2: XAFS data for R and k space for $\mathbf{3}$ with corresponding fit calculated in the Artemis program.

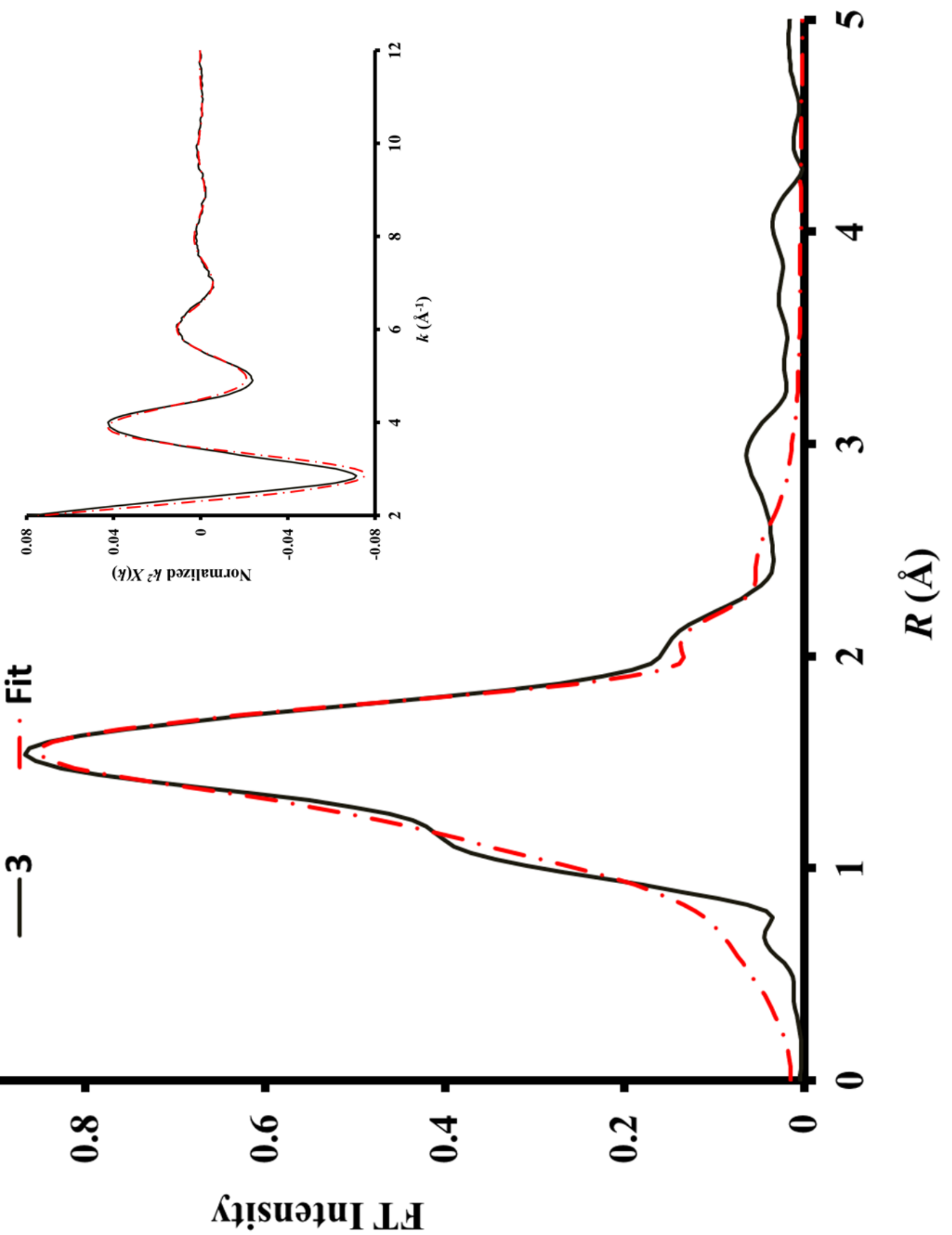


Figure S3: XAFS data in R and k space for $\mathbf{4}$ with corresponding fit calculated in the Artemis program.
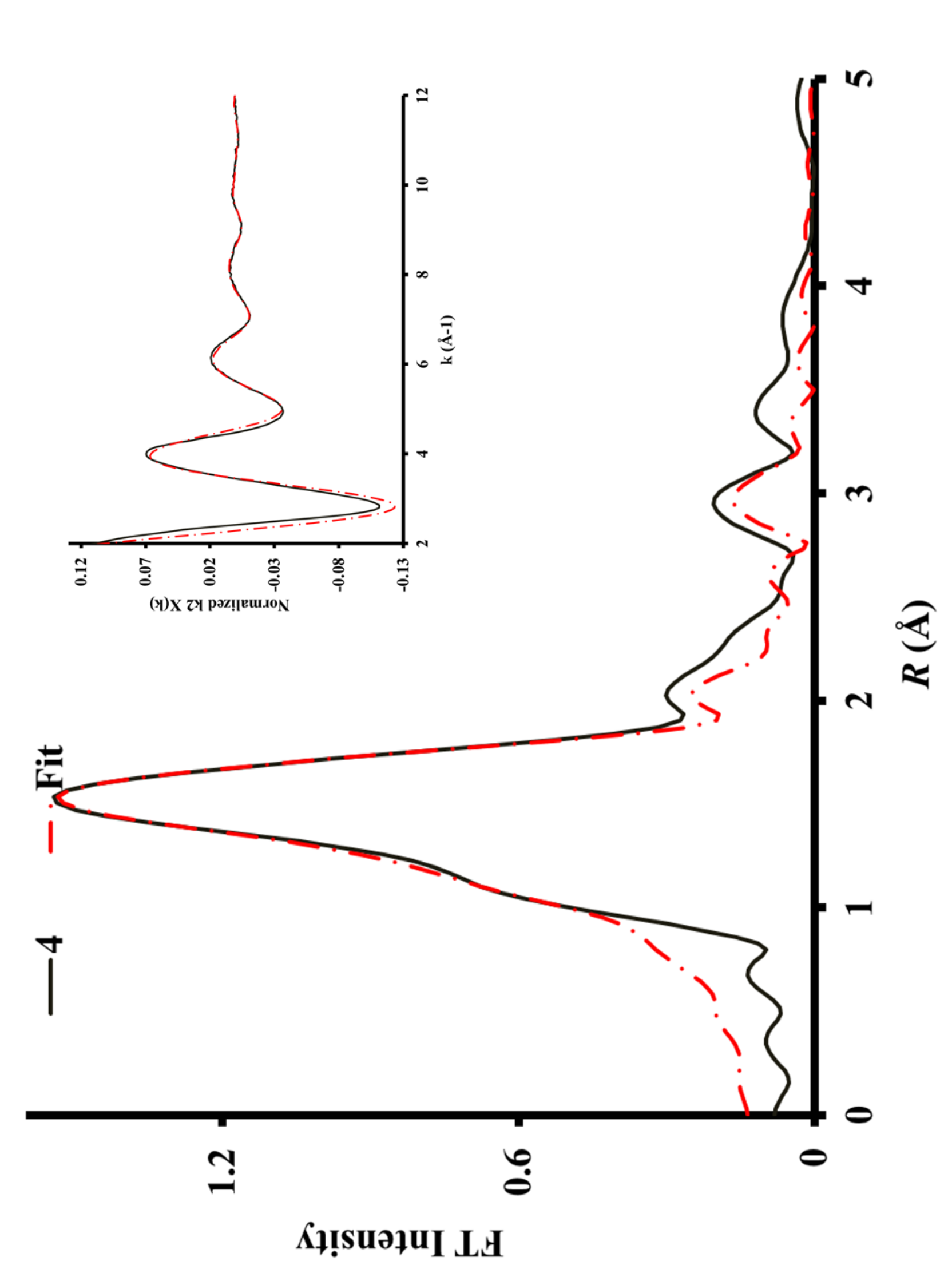
Figure S4: XAFS data in R and k space for $\mathbf{5}$ with corresponding fit calculated in the Artemis program.
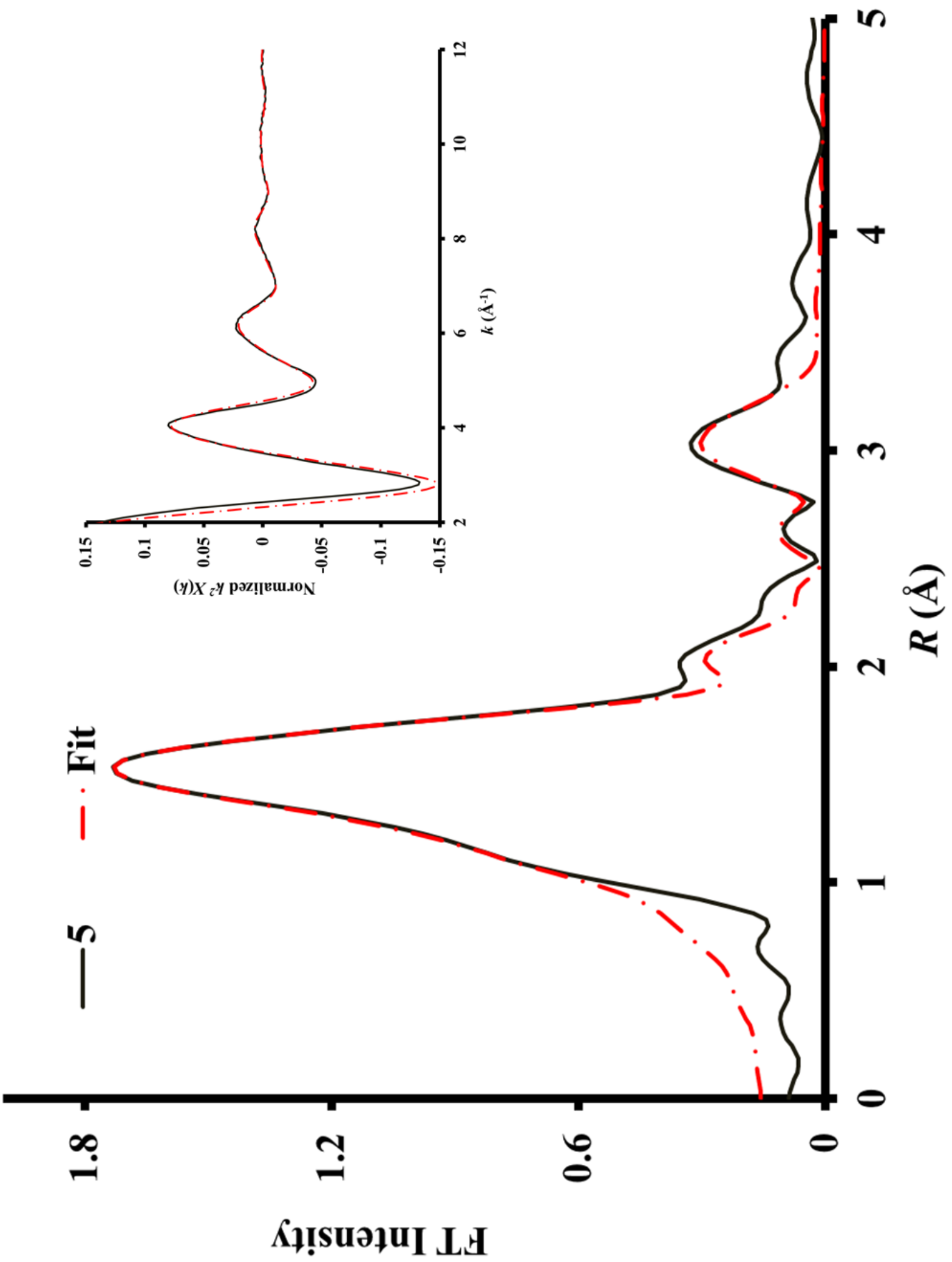
S2. RAMAN SPECTROSCOPY DATA FOR COMPOUNDS 2-7.

Figure S5. Raman spectroscopy data for untreated silica and compound 2.

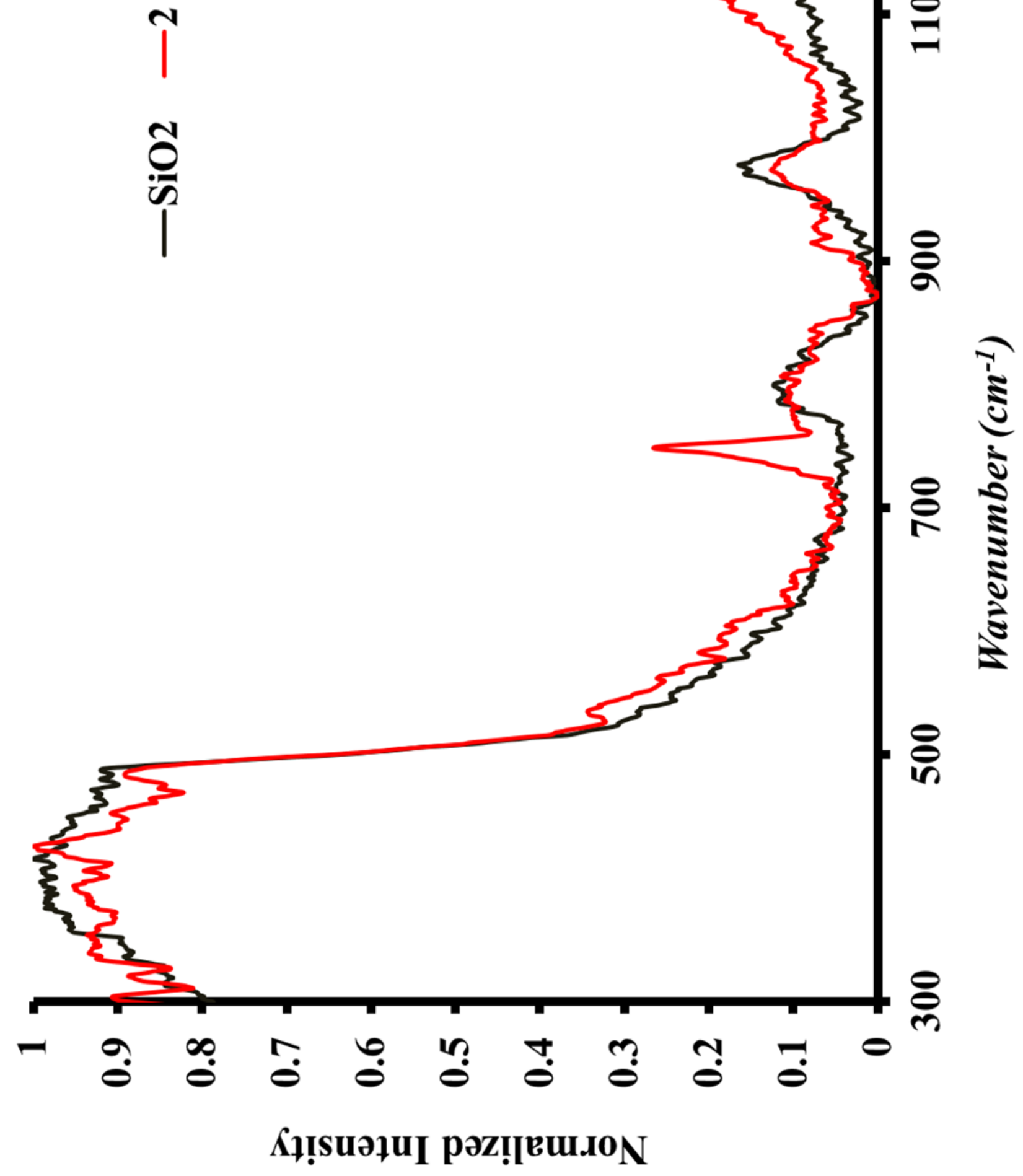


Figure S6. Raman spectroscopy data for $\mathbf{2}, \mathbf{3}$, and $\mathbf{3}$ with $2^{\text {nd }}$ addition of $\mathbf{1}$.

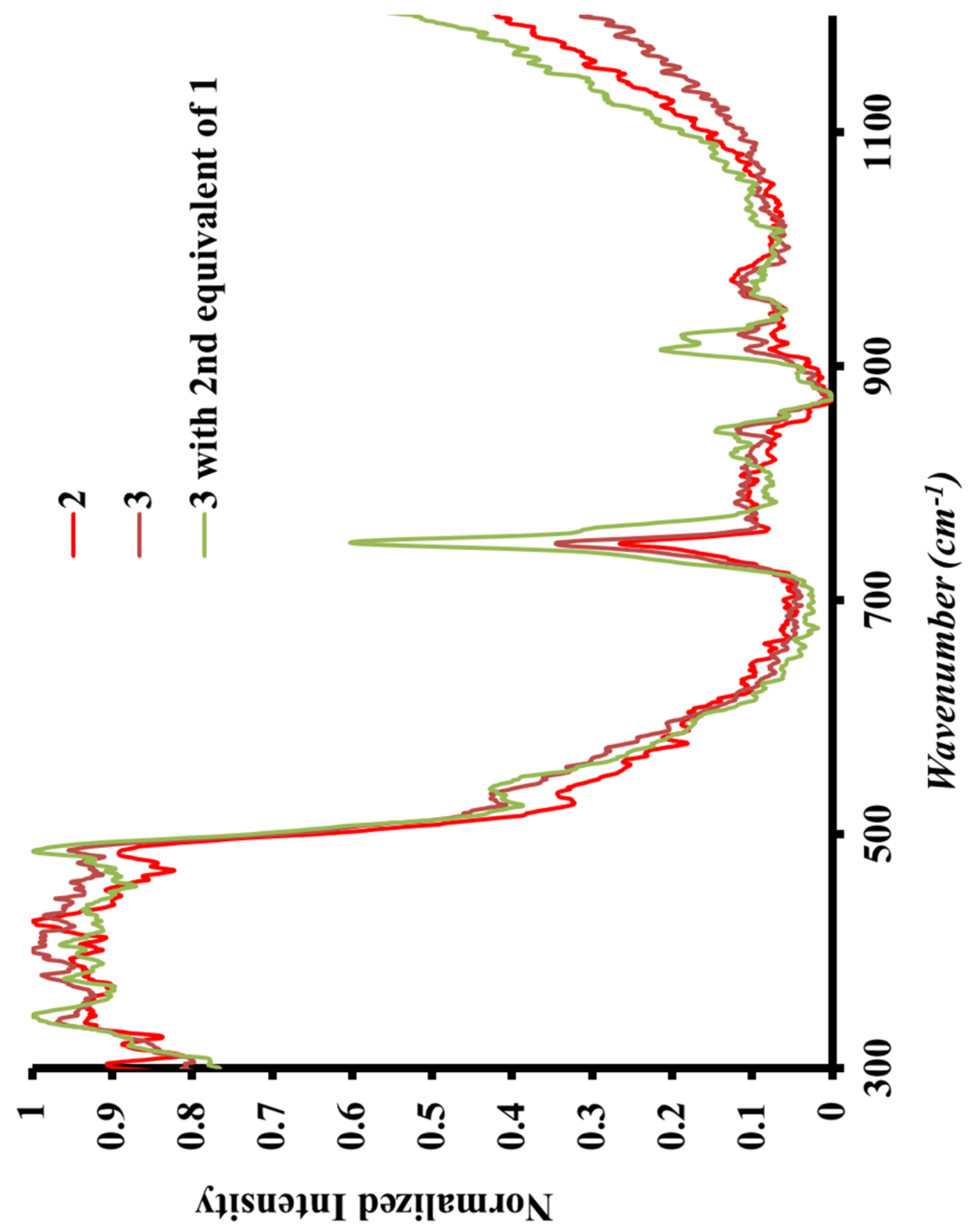


Figure S7. Raman spectroscopic data for 2, 4, and 6.

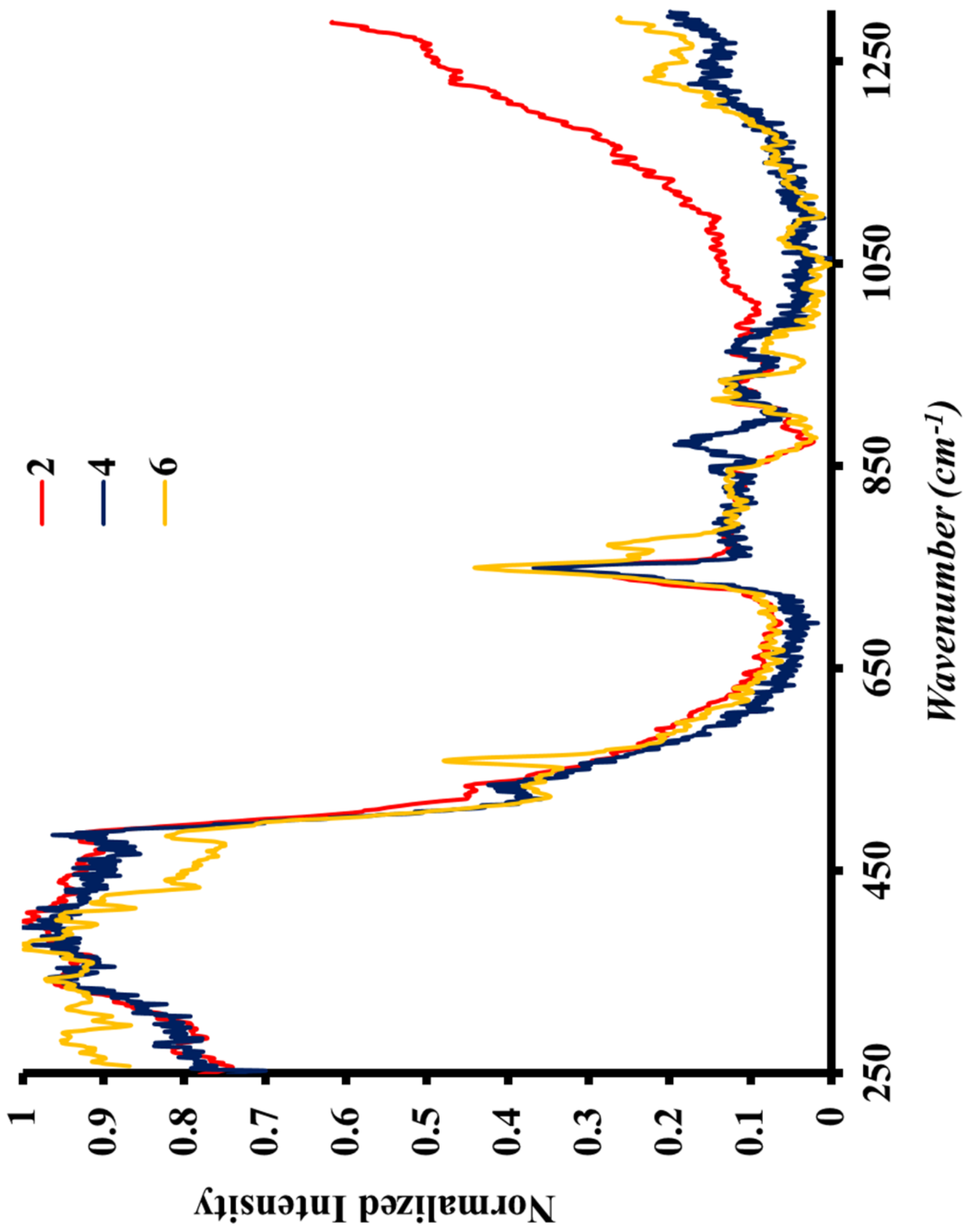


Figure S8. Raman spectroscopic data for 2, 5, and 7.

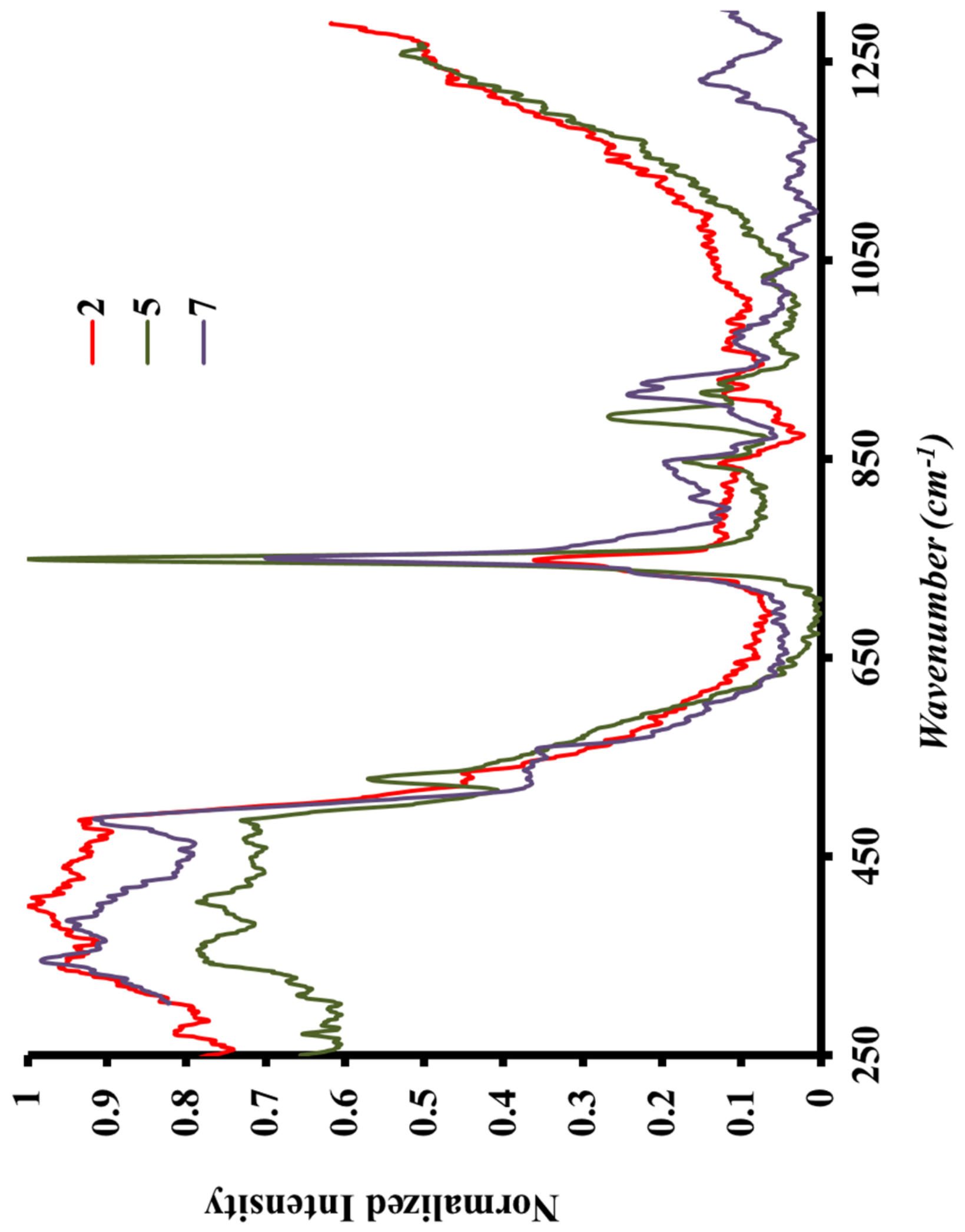


S3. DIFFUSE REFLECTANCE INFRARED FOURIER TRANSFORM SPECTROSCOPY (DRIFTS) DATA FOR COMPOUNDS 3 AND 5.

Figure S9. Diffuse reflectance infrared Fourier transform spectroscopy (DRIFTS) data for $\mathbf{3}$ with background subtractions of high surface area silica and 2.

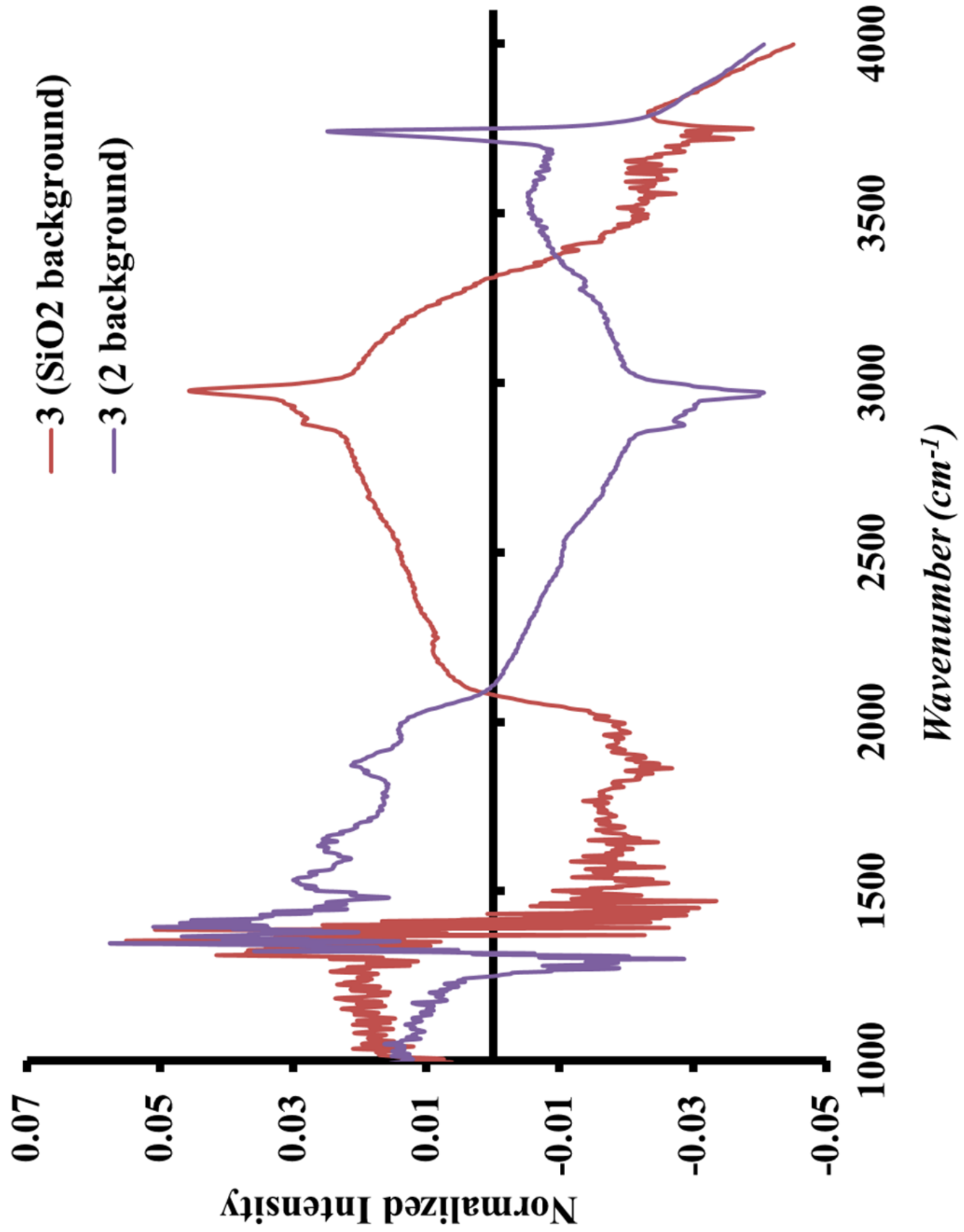


Figure S10. Diffuse reflectance infrared Fourier transform spectroscopy (DRIFTS) data for $\mathbf{5}$ with background subtractions of high surface area silica and 2.

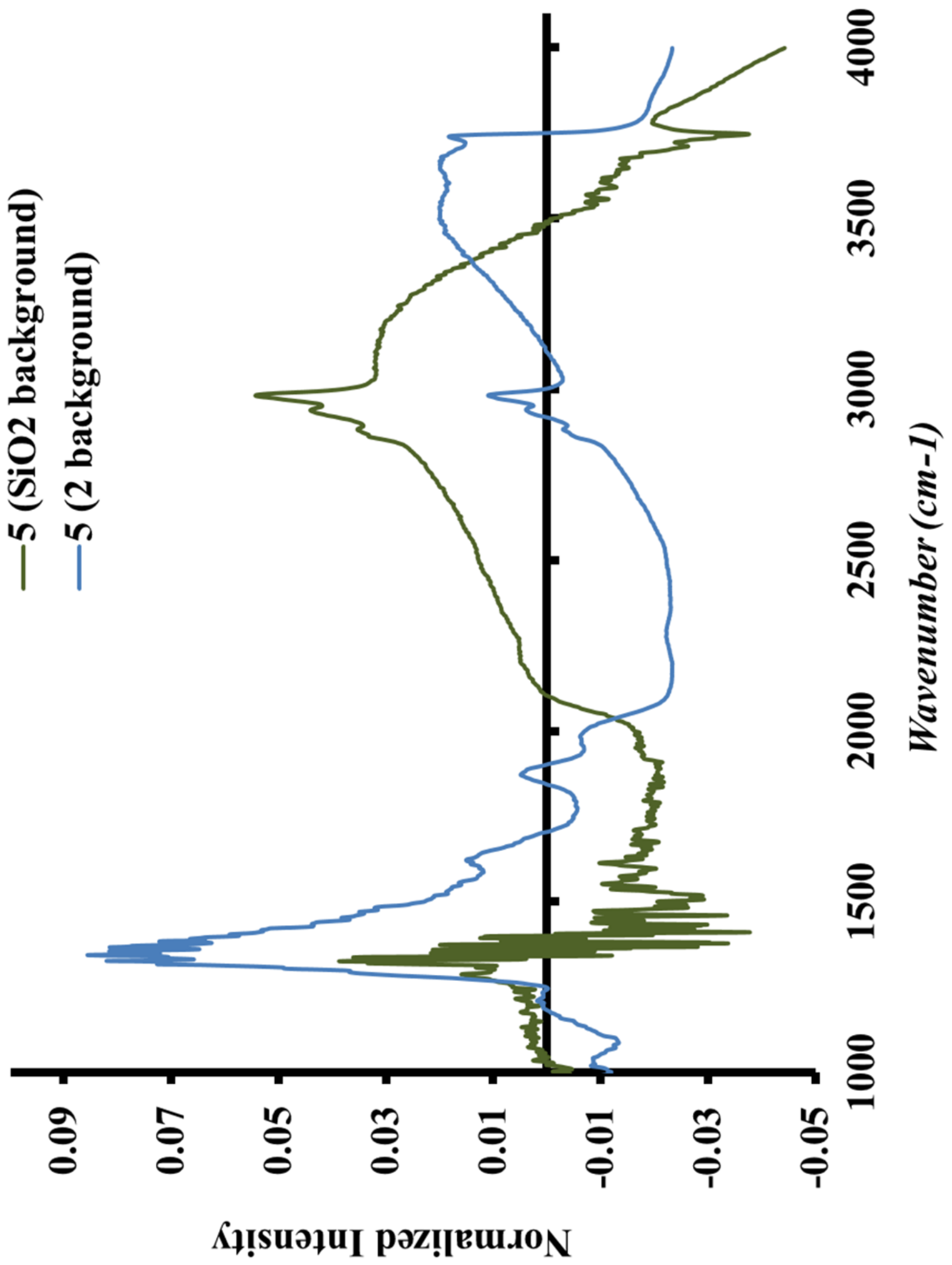

